\title{
The Angiotensin II Receptor Antagonist Candesartan Is Not Effective in Reducing Portal Hypertension in Patients with Cirrhosis
}

\author{
Markus H. Heim ${ }^{a} \quad$ Ludwig Jacob $^{b} \quad$ Christoph Beglinger ${ }^{a}$ \\ a Division of Gastroenterology and Hepatology, and ${ }^{b}$ Department of Radiology, University Hospital Basel, \\ Basel, Switzerland
}

Dear Sir,

Non-selective $\beta$-blockers are widely used for the prevention of variceal bleeding in patients with portal hypertension. However, a substantial proportion of patients cannot be treated effectively because of side effects or an insufficient reduction in portal pressure. The renin-angiotensinaldosterone system is activated in many patients with cirrhosis and has been involved in the pathogenesis of portal hypertension and liver fibrogenesis. Losartan, an oral angiotensin II (ATII) receptor antagonist, was found to substantially lower the portal pressure within 1 week in patients with severe and moderate portal hypertension [1]. However, these very promising results could not be confirmed in a randomized trial comparing losartan with propranolol over a 6-week observation period [2]. Candesartan is another ATII receptor antagonist approved for the treatment of arterial hypertension. In vitro, candesartan is more potent in blocking the ATII type-1 receptor than losartan [3]. The aim of the present study was to examine the antihypertensive effect of candesartan on portal pressure in patients with cirrhosis and an indication for primary or secondary prevention of variceal bleeding.
Seventeen patients with biopsy-proven cirrhosis and an indication for medical prevention of variceal (re-)bleeding gave written informed consent to participate in the study. Exclusion criteria were: quick $<40 \%$; platelet count $<50,000$; bleeding time $>15$ min; portal vein thrombosis; liver vein thrombosis; hepatic venous pressure gradient (HVPG) measurement not feasible; hepatic encephalopathy of $>1$; renal insufficiency (creatinine $>133 \mu \mathrm{mol} /$ 1); ongoing antihypertensive therapy (ACE inhibitors, $\beta$-blockers, $\mathrm{Ca}$ antagonists, nitrates, $\alpha$-blockers); therapy with theophylline, papaverine, tricyclic antidepressants; contraindications to candesartan, and pregnancy. The trial was approved by the local ethics committee for human studies. All patients gave a written informed consent. Patients were randomized to receive either $8 \mathrm{mg}$ candesartan or placebo once daily (in the morning) for 7 days. All patients had HVPG measurement 1 day before the start of treatment and on day 7 of treatment, 3-6 $\mathrm{h}$ after ingestion of the study medication. The primary endpoint was a reduction in HVPG after 7 days of treatment. Secondary outcome measures were the safety of candesartan in patients with liver cirrhosis and portal hyperten- sion. Based on the publication of Schneider et al. [1] we made the assumption that the mean HVPG before treatment would be 24 $\mathrm{mm} \mathrm{Hg}$ with a standard deviation of $4 \mathrm{~mm}$ $\mathrm{Hg}$. We further assumed that placebo treatment would not reduce HVPG. A reduction of $25 \%$ (6 $\mathrm{mm} \mathrm{Hg}$ ) in the HVPG by candesartan was regarded as clinically significant. We determined sample size using GraphPad StatMate version 2.00 for Macintosh (GraphPad Software, San Diego, Calif., USA, www.graphpad.com). For a significance level of 0.05 and a power of 0.8 , the calculated sample size was 8 in each group. The results in the candesartan group were compared to the placebo group using the paired $t$ test.

Eight patients were randomized in the treatment group: 4 females, 4 males; 6 with alcoholic cirrhosis, 2 viral cirrhosis; mean age 50 years; mean body mass index 29, and mean HVPG before treatment 22 $\mathrm{mm} \mathrm{Hg}$. Nine patients were randomized in the control group: 2 females, 7 males; 6 with alcoholic cirrhosis, 3 viral cirrhosis; mean age 60 years; mean body mass index 25, and mean HVPG before treatment 27 $\mathrm{mm} \mathrm{Hg}$. Two patients in the candesartan group dropped out because of adverse effects, and no HVPG could be measured

\begin{tabular}{ll}
\hline KARGER & ( ) 2007 S. Karger AG, Basel \\
$0012-2823 / 07 / 0753-0122 \$ 23.50 / 0$ \\
$\begin{array}{l}\text { Fax +4161306 1234 } \\
\begin{array}{l}\text { E-Mail karger@karger.ch } \\
\text { www.karger.com }\end{array}\end{array}$ & $\begin{array}{l}\text { Accessible online at: } \\
\text { www.karger.com/dig }\end{array}$
\end{tabular}

Prof. Markus Heim

Division of Gastroenterology and Hepatology, University Hospital Basel Petersgraben 4

CH-4031 Basel (Switzerland)

Tel. +41 6126525 25, Fax +41 6126553 52,E-Mail markus.heim@unibas.ch 
Fig. 1. Changes in HVPG from baseline after 7 days of treatment with candesartan or placebo are shown for all patients. $\square=$ Controls; $\mathbf{\square}=$ patients receiving candesar$\tan$.

under treatment. One patient had severe atrial fibrillation requiring a cardiological intervention; the second patient developed renal insufficiency after 2 days of therapy. No clinically relevant arterial hypotension was observed in the study patients. The mean HVPG reduction after 7 days of treatment was $3 \mathrm{~mm} \mathrm{Hg}$ in the control group and $1 \mathrm{~mm} \mathrm{Hg}$ in the candesar$\tan$ group. The difference between the groups was not significant. Figure 1 shows the individual values of the reduction in HVPG in mm Hg for all the patients. The spontaneous decrease in HVPG in 3 patients in the placebo group most likely resulted from a spontaneous improvement in the underlying liver disease. All 3 patients suffered from alcohol-toxic liver cirrhosis, and all had ongoing alcohol consumption before their admittance to hospital. Most likely, alcohol abstinence during the hospital stay led to an improvement of the reversible component of portal hypertension caused by the alcoholic hepatitis.

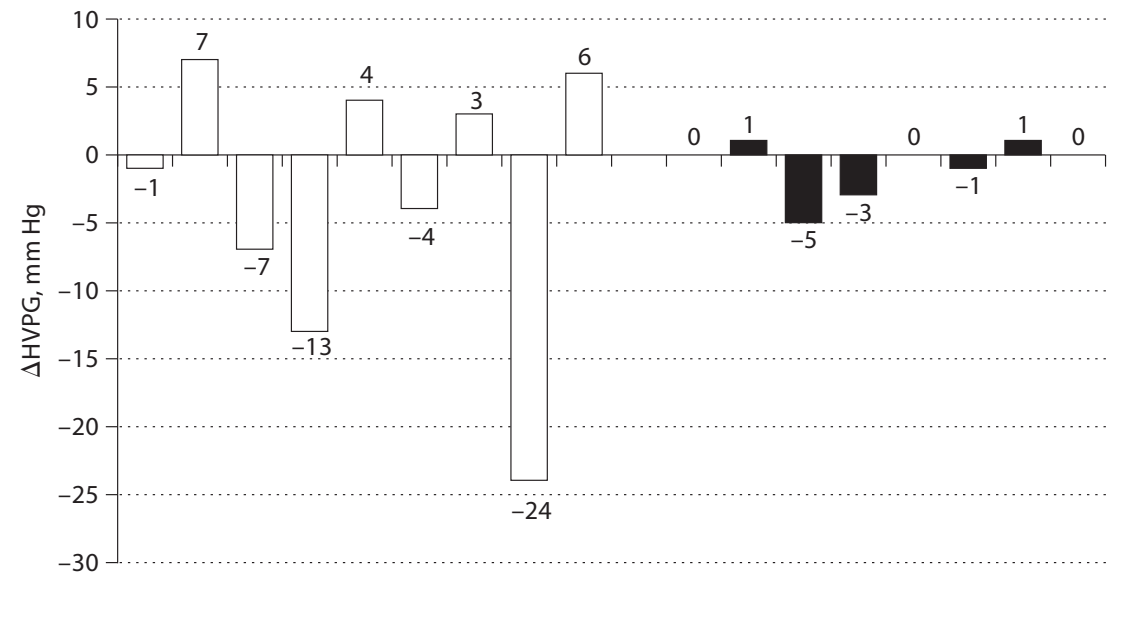

Based on the results of this pilot study we conclude that candesartan is not effective in reducing portal hypertension when given for 1 week. This is in accordance with previous reports showing that two other ATII antagonists, irbesartan and losartan, do not significantly reduce HVPG [2, 4]. We cannot exclude that a higher dose of candesartan (i.e. $16 \mathrm{mg} /$ day) would be more effective for reducing HVPG. However, many cirrhotic patients have low systemic blood pressure, and losartan was found to significantly decrease mean arterial pressure in a previous study [2]. We therefore considered that the risk of inducing clinically significant arterial hypotension in this patient population would be too high when using a $16-\mathrm{mg}$ dose. It is also noteworthy that already with the 8-mg dose used in this study, one of the patients in the candesartan group developed renal insufficiency. We therefore believe that the use of candesartan is not advisable in patients with cirrhosis and portal hypertension.

\section{References}

1 Schneider AW, Kalk JF, Klein CP: Effect of losartan, an angiotensin II receptor antagonist, on portal pressure in cirrhosis. Hepatology 1999;29:334-339.

2 Gonzalez-Abraldes J, Albillos A, Banares R, et al: Randomized comparison of long-term losartan versus propranolol in lowering portal pressure in cirrhosis. Gastroenterology 2001;121:382-388.

3 Verheijen I, Vanderheyden PM, De Backer $J P$, et al: Antagonist interaction with endogenous AT(1) receptors in human cell lines. Biochem Pharmacol 2002;64:1207-1214.

4 Schepke M, Werner E, Biecker E, et al: Hemodynamic effects of the angiotensin II receptor antagonist irbesartan in patients with cirrhosis and portal hypertension. Gastroenterology 2001;121:389-395. 